\title{
Optimality-Theoretic Analysis of Syllabic Adaptation of English Loanwords in Standard Kiswahili
}

\author{
Saleh Batais* \\ Department of English Language \& Literature, College of Arts, King Saud University, Riyadh, Saudi Arabia \\ *Corresponding Author: Saleh Batais, Department of English Language \& Literature, College of Arts, \\ King Saud University, Riyadh, Saudi Arabia
}

\begin{abstract}
Based on lists of well-established English loanwords and relying on Optimality Theory, this paper investigates the syllabic adaptation of problematic structures of English loanwords in Standard Kiswahili. It has been found that word-final singleton and complex codas are never tolerated in Kiswahili; therefore, they are repaired via edge vowel epenthesis (e.g., /ti.mu/ "team"; /lif.ti/ "lift"), displaying a strong preference for open syllables (i.e., NOCODA\#) and syllable contact pairs in Kiswahili (i.e., SYLLCONT) and maintaining the contiguity of corresponding segments in the input and the output (i.e., ConTIGUITY-IO). With respect to the type of the epenthetic vowel, it is either coronal /i/ (e.g., /pla.ni/ "plan") or labial /u/ (e.g., /gra.mu/ "gram") depending on the place feature (i.e., coronal or labial) of the consonant immediately to its left (i.e., AGREEL(CPL)). Finally, word-initial singleton and complex onsets remain intact in English loanwords (e.g., /kla.bu/ "club"), revealing the importance of the onset (i.e. ONSET) requirement in Kiswahili and obeying input contiguity (i.e., CONTIGUITY-IO), sonority sequencing principle (i.e., SON-SEQ), and syllable contact law (i.e., SYLLCONT)-which all might be violated if edge/medial vowel epenthesis was triggered to adapt onset consonants in English loanwords.
\end{abstract}

Keywords: Optimality Theory, Loanwords, Adaptation, Syllabic Repair, English, Kiswahili

\section{INTRODUCTION}

Belonging to the Bantu language family, Kiswahili is widely spoken by millions of native and secondlanguage speakers in East and Central Africa. Of all dialects of Kiswahili, the Kiunguja dialect, spoken in Zanzibar, was selected to be the standard dialect (i.e., Standard Kiswahili) and is nowadays used in government offices, schools, mass media, and courts of law [1], [2], [3],[4], [5],[6],[7],[8], [9],[10].

For many years, Kiswahili has been in varying degrees of contact with non-Bantu languages, primarily triggered by trade and colonization. As a result, a large number of words were directly borrowed into Kiswahili from Arabic, English, Portuguese, German, Persian, Hindi, Malay, and Turkish. In terms of the percentage of lexical contribution to Kiswahili vocabulary, Arabic is the largest donor, while Portuguese, German, Persian, Hindi, Malay, and Turkish are the smallest [6], [11], [7], [10]. With respect to English words, according to Petzell [11], they account for the largest number of recent borrowings in Kiswahili to designate complex concepts, novel objects, and technical terms.

Foreign words are usually subject to adaptation when borrowed into the native language. The phonological adaptation processes operate to bring the problematic foreign form in conformity with the phonology of the native borrowing language. The repaired foreign form can be a segment, syllable, or a suprasegmental feature. In this paper, using Optimality Theory (henceforth, OT), I explore the syllabic repair strategy of vowel epenthesis employed by Standard Kiswahili to adapt English loanwords entering its lexicon. I discuss that vowel epenthesis is triggered only to resolve English word-final singleton and complex coda positions which are problematic in light of Kiswahili phonotactics. The only type of vowel epenthesis attested in the data is edge vowel epenthesis. In OT terms, the adaptation of word-final coda position via edge epenthesis is captured by ranking DEP-IO (V) (triggering vowel epenthesis) below high-ranked NoCoDA\#(favoring open syllables), CONTIGUITY-IO (preventing medial vowel epenthesis), and MAX-IO (C) (avoiding consonant deletion as a repair strategy). 
Moreover, I argue that the type of epenthetic vowel resulting from edge vowel epenthesis matches the place feature of that of the immediately preceding consonant. Coronal $/ \mathrm{i} / \mathrm{or}$ labial $/ \mathrm{u} / \mathrm{is}$ used in the epenthetic site if the consonant immediately to the left is coronal or labial, respectively. In addition, coronal/i/ is inserted after velar consonants, following from the claim that word-final velar consonants are not represented for a place feature [12], [13]. This featural agreement between the epenthetic vowel and the immediately preceding consonant is determined by the ranking of AGREE-L (CPL) and $* \mathrm{C}_{\mathrm{VelaR}} \mathrm{V}_{\text {LABIAL }} \#$ above DeP-IO $(\mathrm{V})$.

Regarding word-initial (singleton or complex) onsets in English loanwords, they are unadapted in Kiswahili, reflecting the significant tendency in Kiswahili to have onsets. The Kiswahili preference for both singleton and complex onsets and their non-adaptation in English loanwords is achieved without violating higher-ranked ONSET, CONTIGUITY-IO, SON-SEQ (encouraging rising sonority with onset consonants), and SYLLCONT (motivating falling sonority across syllable boundaries).

The remainder of the paper is organized as follows: Section 2 gives an overview of syllable structures in Standard Kiswahili. Section 3 describes the sources from which the data used in this paper were gathered. Section 4 discusses and presents an Optimality-Theoretic analysis of the attested syllabic repair processes. Section 5 concludes the discussion.

\section{SWAHILI PHONOTACTICS}

The preferred syllable structure in Kiswahili is (C) (C) (C) V[14],[3],[4],[5],[6],[7],[15],[10] $]^{1}$. The nucleus can be taken up by any vowel. Examples of Kiswahili words of V-syllable structure are /o.a/ "marry" and /a.bi.ri/ "to cross". In addition, pre-consonantal $/ \mathrm{m} / \mathrm{and} / \mathrm{n} / \mathrm{can}$ function as the nucleus of the syllable (e.g., /m. tu/ "a person" and /n.tgi/ "country"). In CV-syllables, C can be any consonant, as in /pa.ka/ "cat" and /mi.ti/ "trees"). Consonant clusters are only permitted syllable- or word-initially. CCV-syllables in native Kiswahili occur when the first consonant in the CC cluster is a nasal consonant followed by an oral consonant (e.g., /ma.mba/ "crocodile" and /nga.mi.a/ "camel") or when the first consonant is an oral consonant followed by a glide (e.g., /ku.bwa/ "big" and /kwa.ni/ "why"). Finally, the CCCV-syllable type in native Kiswahili words is usually restricted to clusters where a nasal consonant is the first consonant and a glide is a third (e.g., /f fu.ngwa/ "orange" and /ti.mbwa/ "booted").

\section{DATA}

The primary sources of data for this paper are Awde's (2002) Swahili-English English- Swahili Dictionary[16], Mohamed's (2011) Comprehensive Swahili-English Dictionary[17], and Dr. M. Matondo (personal communication, April 17, 2010).Matondo's data are compiled lists of words (transcribed in IPA) borrowed into Standard Kiswahili and Standard Kisukuma from various languages: Arabic, English, Portuguese, French, German, Greek, Hindi, Turkish, and Persian.

\section{ANALYSIS AND DiscusSiON}

In this section, a standard Optimality Theory approach is used to account for the syllabic adaptation of English loanwords in Kiswahili and the factors involved in the choice of optimal outputs. To begin with, consider the English loanwords in (1):

(1) /ti.mu/ timu "team"
/bu.ti/
/tgo.ki/ chaki "boot"

As illustrated in (1), the codas in the source (English) forms are avoided in Kiswahili through vowel epenthesis; that is, each coda is now syllabified as the onset of the second syllable. Moreover, the source coda consonants are never resolved through consonant deletion.

Given that the maximal Kiswahili syllable is $\mathrm{CCCV}$, the following four constraints are required to explain the dataset in (1) using OT:

NOCODA\#: Word-final syllables should not end in a singleton consonant/ consonant cluster (i.e., word-final syllables should be open).

ONSET: Each syllable should have an onset (a singleton consonant/ consonant cluster).

\footnotetext{
${ }^{1}$ Examples in this section are drawn from these sources.
} 
DEP-IO (V): Vowels in the output have a corresponding vowel in the input (i.e., insertion of a vowel is not allowed).

MAX-IO(C): Consonants in the input have a correspondent consonant in output(i.e., deletion of a consonant is not allowed)

As shown in Tableau (1), the ranking of both the markedness constraints NOCODA\# and ONSET as well as the faithfulness constraint MAX-IO(C) above the faithfulness constraint DEP-IO (V) motivates vowel epenthesis as a resolution to words ending in codas and favors onset syllabification:

Table1: Vowel epenthesis in inputs with word-final codas

\begin{tabular}{|l|l|l|l|l|}
\hline Input: /tim/ & NOCODA\# & ONSET & MAX-IO(C) & DEP-IO (V) \\
\hline a. /tim/ & $* !$ & & & \\
\hline b. $/$ ti.mu/ & & & & $*$ \\
\hline c. /ti/ & & & $* !$ & \\
\hline d. /tim.u/ & & $* !$ & & \\
\hline
\end{tabular}

In Tableau (1), candidate (b) is the winning output because it is optimally syllabified, satisfying the high-ranked constraints NOCODA\#, ONSET, and MAX-IO(C), the violation of which results in the losses of candidates (a), (c), and (d). Since vowel epenthesis in Kiswahili is preferred over consonant deletion as a repair strategy to avoid codas in English loanwords, DEP-IO (V) is violable and is thus ranked lowest. The ranking of the four constraints is as follows: NOCODA\#, ONSET >>MAX$\mathrm{IO}(\mathrm{C})>>$ DEP-IO $(\mathrm{V})$.

Moreover, in some English loanwords, singleton consonants are evident in coda positions of wordinitial syllables, as exemplified in (2):

(2) /lif.ti/ lifti "lift"

$\begin{array}{lll}\text { /fil.mu/ } & \text { filmu "film" } \\ \text { /bol.ti / } & \text { bolti "bolt" } \\ \text { /ben.di/ } & \text { bendi "band" } \\ \text { /dan.si/ } & \text { dansi } & \text { "dance" }\end{array}$

After word-final vowel epenthesis is triggered to avoid word-final coda consonant clusters, the words are automatically syllabified so as to allow the first consonant in the source CC cluster to occupy the coda position of the first syllable and the second consonant to take up the onset position of the next syllable. For such syllabification to occur, a) a word-final consonant cluster is simplified via edge vowel epenthesis and b) sonority must drop between the coda consonant and the following onset consonant. According to the Sonority Hierarchy, vowels are the most sonorous sounds followed next by glides/liquids, nasals, fricative, and finally by stops/affricates as the least sonorous. To reformulate such account in OT terms, the following constraints are needed (plus NOCODA\#, ONSET, MAX-IO(C), and $\operatorname{DEP}-\mathrm{IO}(\mathrm{V}))$ :

CODACOND: Singleton codas are allowed in word-initial syllables.

SYLLCONT: Sonority falls across a syllable boundary [18].

CONTIGUITY-IO: Segments adjacent in the input are adjacent in the output (no medial epenthesis/deletion) [19].

SON-SEQ: Complex onsets rise in sonority, and complex codas fall in sonority [19].

In Tableau (2), candidates (a), (b), and (c) are ruled out by high-ranked markedness constraints NoCODA\#, SON-SEQ, and CODACOND, respectively. Candidate (c) also incurs another violation of high-ranked markedness constraint, ONSET. Candidate (e) is eliminated because it violates highranked CONTIGUITY-IO constraint. Thanks to medial vowel epenthesis, nocontiguous string of input segments is copied to candidate (e). With respect to candidate (f), MAX-IO (C) eliminates it, as the word-final consonant cluster is resolved through consonant deletion (a disfavored syllabic repair strategy in Kiswahili). Finally, candidate (d) emerges as the optimal output; it satisfies all of the aforementioned high-ranked constraints as well as the syllable contact "SYLLCONT" constraint. The fact that DEP-IO (V) is violated in the winning candidate motivates its ranking below unviolated NoCodA\#, SON-SEQ, CODACOND, CONTIGUITY-IO, OnSET, SYllCont, and MAX-IO (C). 
Table2: Syllabification of inputs with complex codas after application of vowel epenthesis

\begin{tabular}{|l|l|l|l|l|l|l|l|l|}
\hline Input: /bolt/ & NOCODA\# & $\begin{array}{l}\text { SON- } \\
\text { SEQ }\end{array}$ & CODACOND & $\begin{array}{l}\text { CONTIGUITY- } \\
\text { IO }\end{array}$ & ONSET & SYLLCONT & $\begin{array}{l}\text { MAX- } \\
\text { IO(C) }\end{array}$ & $\begin{array}{l}\text { DEP-IO } \\
\text { (V) }\end{array}$ \\
\hline a. /bolt/ & $* !$ & & & & & & & $*$ \\
\hline b. /bo.lti/ & & $* !$ & & & & & & \\
\hline c. /bolt.i/ & & & $* !$ & & & & & \\
\hline d. $/$ /bol.ti/ & & & & & & & & $*$ \\
\hline e. /bo.lo.ti/ & & & & $* !$ & & & $* * !$ & \\
\hline f. /bo/ & & & & & & & & $* *$ \\
\hline
\end{tabular}

In addition, the constraints CONTIGUITY-IO, SYLLCONT, SONSEQ, and ONSET play a key role in explaining the non-adaptation of word-initial complex onsets in English loanwords in Kiswahili, as exemplified in (3):

$\begin{array}{lll}\text { (3) } / \text { kla.bu/ } & \text { klabu } & \text { "club" } \\ \text { /gri.si/ } & \text { grisi } & \text { "grease" } \\ \text { /kri.ke.ti/ } & \text { kriketi } & \text { "cricket" } \\ \text { /pla.ni/ } & \text { plani } & \text { "plan" } \\ \text { /tra.fi.ki/ } & \text { trafiki } & \text { "traffic" }\end{array}$

As shown in Tableau 3, the afore-mentioned four constraints are undominated in order to generate the optimal candidate, namely candidate (a). CONTIGUITY-IO eliminates candidate (b) after medial vowel epenthesis is triggered to break up the onset cluster/gr/, thus disrupting the contiguous string of input segments. Furthermore, Candidate (c) is ruled out because it violates ONSET and SYLLCONT. Arising from edge vowel epenthesis to simplify word-initial /gr/, the first consonant, /g/, in the cluster is reanalyzed as the coda of the onset-less syllable (hence, violating ONSET), and the second consonant, $/ \mathrm{r} /$, in the cluster becomes the onset of the next syllable. In such case, SYLLCONT is violated since the sonority of the syllabified onset exceeds that of preceding coda. Lastly, candidate (a) is the winning candidate as an effect of obeying high-ranked inviolable constraints: CONTIGUITY-IO, SYLLCONT, SONSEQ, and ONSET.

Table3: Maintenance of onset complex clusters

\begin{tabular}{|l|l|l|l|l|l|}
\hline Input: /gris/ & CONTIGUITY-IO & SYLLCONT & SON-SEQ & ONSET & DEP-IO (V) \\
\hline a. $/$ grisi/ & & & & & $*$ \\
\hline b. /gi.ri.si/ & $* !$ & & & & $* *$ \\
\hline c. /ig.ri.si/ & & $* !$ & & $*$ & $* *$ \\
\hline
\end{tabular}

Finally, with respect to the type of vowel inserted to resolve the word-final coda position, two epenthetic vowels are evident as far as the English loanwords are concerned. These two vowels are /i/ and $/ \mathrm{u} /$, as shown in (4):

$\begin{array}{lll}\text { (4) /ba.si/ } & \text { basi } & \text { "bus" } \\ \text { /be.gi/ } & \text { begi } & \text { "bag" } \\ \text { /da.ze.ni/ } & \text { dazeni } & \text { "dozen" } \\ \text { / Jif.ti/ } & \text { shifti } & \text { "shift" } \\ \text { /gra.mu/ } & \text { gramu } & \text { "gram" } \\ \text { /bal.bu/ } & \text { balbu } & \text { "bulb" } \\ \text { /f fi.fu/ } & \text { chifu } & \text { "chief" }\end{array}$

Based on the dataset in (4), the nature of the epenthetic vowel is determined by the place feature of the word-final consonant in the source English word. That is to say, /u/ is inserted when immediately following word-final [+labial] consonant (i.e., bilabials and labiodentals), while /i/ is epenthesized elsewhere, viz., after a word-final [-labial] consonant (i.e., dentals, alveolars, post-alveolars, palatals, and velars). The same tendency, moreover, holds in other data from Arabic loanwords in Kiswahili [20], [14], [4], [7], [15], [21]). Following Uffmann [12], Rose and Demuth [13], and Harvey [21], I propose that word-final labial consonants contribute a labial place specification to the epenthetic vowel, yielding labial /u/, and word-final coronal consonants spread a coronal vowel place feature to the epenthetic site, resulting in coronal /i/. Furthermore, because word-final velar consonants are not specified for any place feature, coronal place specification is instead copied into the epenthetic site, generating coronal /i/. 
To cast the above observation in OT, the following two constraints, in addition to DEP-IO (V), are required:

AGREEL (CPL): The place feature of the epenthetic vowel matches the place feature of the consonant immediately to its left [22],[13].

$* \mathrm{C}_{\text {VELAR }} \mathrm{V}_{\text {LABIAL }} \#$ : A word-final sequence of a velar consonant and a labial vowel is not tolerated.

Table4: The type of word-final epenthetic vowel

\begin{tabular}{|c|c|c|c|c|}
\hline 1. & Input: /b $\Lambda \mathrm{s} /$ & AGREEL (CPL) & $* \mathrm{C}_{\mathrm{VELAR}} \mathrm{V}_{\mathrm{LABIAL}} \#$ & DEP-IO (V) \\
\hline a. & /ba.si/ & & & $*$ \\
\hline b. & /ba.su/ & $* !$ & & $*$ \\
\hline 2. & Input: /græm/ & & & \\
\hline a. & /gra.mu/ & & & $*$ \\
\hline b. & /gra.mi/ & $* !$ & & $*$ \\
\hline 3. & Input: /bæg/ & & & \\
\hline a. & /be.gi/ & & & $*$ \\
\hline b. & /be.gu/ & & $* !$ & $*$ \\
\hline
\end{tabular}

That DEP-IO $(\mathrm{V})$ is violated in the optimal outputs in Tableau 4 motivates the following ranking: AGREEL $(\mathrm{CPL}),{ }^{*} \mathrm{C}_{\text {Dorsal }} \mathrm{V}_{\text {LABIAL }} \#>$ DEP-IO $(\mathrm{V})$. Such ranking guarantees the occurrence of vowel epenthesis, and determines the type of the word-final epenthetic vowel based on the place feature of the immediately preceding consonant. For instance, in Tableau 4, candidates (1a) and (2a) are winning candidates because they satisfy the two high-ranked constraints, resulting in the epenthesis of coronal /i/ after coronal /s/ in (1a) and labial / $\mathrm{u} /$ after labial $/ \mathrm{m} /$ in (2a). Violation of AGREEL (CPL), by inserting a vowel with a place specification different from that of the final consonant, automatically rules out candidates (1b) and ( $2 b)$, in which labial /u/ and coronal /i/ are inserted after coronal /s/ and labial $/ \mathrm{m} /$, respectively.

Lastly, because word-final velar consonants do not contribute a dorsal place specification to the epenthetic site [12], [13], coronal /i/, the most frequently word-final epenthetic vowel in both English and Arabic loanwords in Kiswahili, is instead inserted. The insertion of coronal /i/ after velar consonants satisfies high-ranked ${ }^{*} \mathrm{C}_{\mathrm{VELAR}} \mathrm{V}_{\mathrm{LABIAL}} \#$, generating the optimal candidate (3a), whereas inserting a vowel other than coronal /i/ violates it and causes candidate ( $3 b$ ) to lose (in which labial /u/ is inserted). It is worth adding that inserting coronal $/ \mathrm{i} /$ or labial $/ \mathrm{u} / \mathrm{after}$ velar $/ \mathrm{g} /$, as in candidates (3a) and (3b), respectively, does not incur a violation of AGREEL (CPL). This is because AGREEL (CPL) is activated only if the word-final consonant has a place specification.

\section{CONCLUSION}

In this paper, using Optimality Theory, I examine and account for the syllabic adaptation of English loanwords in Standard Kiswahili. In view of the maximum syllable template, (C) (C) (C) V, in native Kiswahili, word-final coda positions in English loanwords are never tolerated. Influenced by the preference for open syllables and input contiguity, and in accordance with the syllable contact law and the sonority sequencing principle, edge vowel epenthesis, not medial vowel epenthesis or consonant deletion, takes place to resolve such problematic codas. This motivates the higher ranking of inviolable NoCoda\#, Contiguity-IO, SyllCont, SON-SEQ, and MAX-IO above DeP-IO (V). Moreover, word-medial singleton codas in bisyllabic and multisyllabic words are attested in the data, resulting from edge vowel epenthesis followed by the reanalysis of the first consonant in the CC cluster as the coda of the first syllable and the second consonant as the onset of the next syllable. The occurrence of such codas is restricted to coda positions in word-initial syllables and is governed by high-ranked Coda Condition (CODACOND) constraint.

With regard to onsets in English loanwords in Kiswahili, they remain unadapted, driven mainly by the need for onset consonants with rising sonority and by the ban against edge/medial vowel epenthesis targeting onsets. The non-adaptation of onsets is guaranteed by the dominance of ONSET, SON-SEQ, SYLLCONT, and CONTIGUITY-IO over DEP-IO (V). Finally, concerning the word-final epenthetic vowel, it receives its place feature from the consonant immediately to the left. If that consonant is represented with the labial place feature, labial $/ \mathrm{u} /$ is used in the epenthetic site; however, if the consonant to the left is specified for the coronal place feature, then coronal / $\mathrm{i} /$ is inserted. In the cases where the immediately preceding consonant lacks a place specification (such as velars) and hence cannot contribute a place feature to the epenthetic site, coronal /i/ is inserted by default. The matching in place feature between the epenthetic vowel and the consonant on the left, as well as the occurrence 
of word-final coronal /i/ immediately after velar consonants, is ensured by the ranking of both AgREEL (CPL) and $* \mathrm{C}_{\mathrm{VelaR}} \mathrm{V}_{\text {LABIAL }} \#$ above Dep-IO (V).

\section{REFERENCES}

[1] Myachina, E. (1981). The Swahili language: A descriptive grammar. London: Routledge \& Kegan Paul.

[2] Vitale, A. (1981). Swahili syntax. Dordrecht, the Netherlands: Foris Publications.

[3] Perrott, D. (1992). Swahili. Lincolnwood, IL: NTC Publishing Group.

[4] Kharusi, N. (1994). The linguistic analysis of Arabic loanwords in Swahili. Doctoral dissertation, Georgetown University.

[5] Contini-Morava, E. (1996). "Swahili phonology". In A. Kaye, \& P. Daniels (Eds.), Phonologies of Asia and Africa: including the Caucasus (pp 841-860). Winona Lake, Indiana: Eisenbrauns.

[6] Mohamed, M. (2001). Modern Swahili grammar. Nairobi, Kenya: East African Educational Publishers Ltd.

[7] Coate, D. (2006). Lexical borrowing in Swahili from Arabic. Master's thesis, Truman State University.

[8] Schadeberg, T. (2009). Loanwords in Swahili. In M. Haspelmath, \& U. Tadmor (Eds.),Loanwords in the world's languages: A comparative handbook (pp 76-102). Berlin: De Gruyter Mouton.

[9] Maganda, D., \& Moshi, L. (Eds.). (2014). Swahili people and their language: A teaching handbook. Asokoro, Nigeria: Adonis \& Abbey Publishers Ltd.

[10] Mwaliwa, H. (2014). An analysis of the syllable Structure of Standard Kiswahili loanwords from Modern Standard Arabic. Doctoral dissertation, University of Nairobi.

[11] Petzell, M. (2005). Expanding the Swahili vocabulary. Africa \& Asia: GöteborgWorking Papers on Asian and African Languages, 5, 85-107.

[12] Uffmann, C. (2004). Vowel epenthesis in loanword phonology. Doctoral dissertation, Philipps-Universita"t Marburg.

[13] Rose, Y.,\&Demuth, K. (2006). Vowel epenthesis in loanword adaptation: Representational and phonetic considerations .Lingua, 116, 1112-1139.

[14] Polomé, E.C. (1967). Swahili language handbook. Washington, DC: Center for Applied Linguistics.

[15] Mwita, L. (2009). The adaptation of Kiswahili loanwords from Arabic: A constraint-based analysis. The Journal of Pan African Studies, 2(8), 46-61.

[16] Awde, N. (2002).Swahili-English English-Swahilidictionary. New York, Hippocrene Books INC.

[17] Mohamed, M. (2011).Comprehensive Swahili-English dictionary. Nairobi, Kenya: East African Educational Publishers Ltd.

[18] Murray, R., \& Vennemann, T. (1983). Sound change and syllable structure in Germanic phonology. Language 59, 514-528.

[19] Kager, R. (1999). Optimality theory. Cambridge: Cambridge University Press.

[20] Tucker, A. (1946). Foreign sounds in Swahili. Bulletin of the School of Oriental and African Studies, 12, 214-232.

[21] Harvey, A. (2014). Epenthetic vowels in Swahili loanwords.Journal of Linguistics and Language in Education, 8 (2), 17-45.

[22] Lombardi, L. (1990). The nonlinear organization of the affricate. Natural Language \& Linguistic Theory, $8,375-425$.

\section{AUTHOR's BIOGRAPHY}

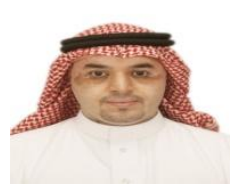

Saleh Batais is an assistant professor of linguistics in the Department of English Language and Literature, at King Saud University, Riyadh, Saudi Arabia. His research interests span the areas of phonological theory, African/Austronesian loanword phonology, language contact, lexical borrowing, and historical linguistics.

Citation: Saleh Batais. Optimality-Theoretic Analysis of Syllabic Adaptation of English Loanwords in Standard Kiswahili. "International Journal on Studies in English Language and Literature (IJSELL), vol 7, no. 7, 2019, pp. 4-9. doi: http://dx.doi.org/10.20431/2347-3134. 0707002.

Copyright: () 2019 Authors. This is an open-access article distributed under the terms of the Creative Commons Attribution License, which permits unrestricted use, distribution, and reproduction in any medium, provided the original author and source are credited. 